\title{
Educação de jovens e adultos - (EJA) - seus impasses e suas contradições
}

\author{
Maria Clara Ramos Nery', Juliana de Oliveira Pereira², Patricia Guerreiro² \\ ' Prof. adjunta com doutorado do Curso de Pedagogia-Graduação-Licenciatura e curso de Especialização - Gestão - \\ Supervisão e Orientação; Universidade Estadual do Rio Grande do Sul - Unidade de Cruz Alta/RS \\ E-mail: ramosnerymariaclara@gmail.com \\ ${ }^{2}$ Graduanda do Curso de Pedagogia - Licenciatura; Universidade Estadual do Rio Grande do Sul - Unidade de Cruz Alta/RS \\ E-mails: ju_pereira30@hotmail.com, pati_guerreiro@hotmail.com.
}

Submetido em: 17 fev. 2019. Aceito: 21 out. 2019. DOI: http://dx.doi.org/I0.21674/2448-0479.61.29-4I

\section{Resumo}

Este artigo é resultado de observação de campo em turmas de EJA. Nossas questões investigativas são: Quais as mediações pedagógicas possíveis para o efetivo ensino na Educação de Jovens e Adultos - EJA? Estão livres de impasses e contradições? O objetivo geral foi abordar os impasses e as contradições existentes no contexto das escolas da Educação de Jovens e Adultos (EJA), que no âmbito de nossa realidade está a perder espaço significativo de inserção social e de posse do conhecimento para aqueles que em tempo "regular" de suas vidas, não puderam dar seguimento em seus estudos. A atividade de observação de campo foi realizada numa escola estadual de Cruz Alta/RS., onde se verificou práticas didático-pedagógicas realizadas numa turma de Ensino Médio - T9, em aula de Matemática e em aula de História, com distintas mediações pedagógicas. Teórico-metodologicamente laborou-se com estudo de caso, buscando, responder adequadamente às nossas questões investigativas e com autores que investigam a questão EJA no Brasil, os quais estão citados no texto. Como resultado pôde-se constatar duas situações distintas de mediação pedagógica: uma prática de ensino-aprendizagem alicerçada na didática tradicional (bancária), e outra prática alicerçada no contexto de vida dos alunos. Como resultado do trabalho investigativo: constatamos ser acanhado o número de professores preparados para ministrar aula em turmas de EJA, dada sua especificidade, sendo o processo de mediação pedagógica embasado em decisão pessoal do professor, bem como apuramos rara capacitação dos professores para o exercício de seu trabalho com alunos da EJA, gerando impasses e contradições.

Palavras-chave: EJA. Contexto. Impasses. Contradições.

\section{Abstract}

\section{Education of youth and adults - (eja) - its impasses and their contradictions}

This article results from field observation in EJA classes. Our research questions are: What are the pedagogical mediations possible for effective teaching in Youth and Adult Education - EJA? Are they free from impasses and contradictions? The general objective was to address the impasses and contradictions that exist in the context of the Schools of Youth and Adult Education (EJA), which in the context of our reality is losing significant space of social insertion and possession of knowledge for those who " regular "of their lives, could not follow up on their studies. The field observation activity was carried out at a state school in Cruz Alta / RS, where didactic-pedagogical practices were observed in a high school class T9, in Mathematics class and in History class, with different pedagogical mediations. Theoretically-methodologically, we 
worked with a case study, seeking to respond adequately to our investigative questions and with authors investigating the EJA issue in Brazil, which are cited in the text. As a result, two distinct pedagogical mediation situations can be observed: a teaching-learning practice based on traditional didactics (banking), and another practice based on the students' life context. As a result of the investigative work: we verified that the number of teachers prepared to teach classes in EJA classes, due to their specificity, was low, and the pedagogical mediation process was based on a personal decision of the teacher, as well as the rare training of teachers for the exercise of his work with EJA students, generating impasses and contradictions.

Keywords: EJA. Context. Impasses. Contradictions.

\section{Introdução}

Este artigo resulta de observação de campo, realizada em uma escola Estadual do Município de Cruz Alta/RS, em turma de Ensino Médio - T9, com 28 alunos matriculados, sendo que no dia da observação estavam presentes 17 alunos, nas disciplinas de Matemática e na de História, estavam presentes 15 alunos. A observação mencionada resulta de atividade letiva do componente de Educação em Ciências Sociais - EJA (Educação de Jovens e Adultos), do oitavo semestre, do Curso de Pedagogia- Licenciatura da Universidade Estadual do Rio Grande do Sul - UERGS. Resulta de inquietações dos futuros pedagogos diante da realidade do ensino da EJA no contexto da sociedade brasileira e do campo educacional brasileiro.

O Plano Nacional de Educação (PNE), por diferenciadas óticas tem sido alvo discussões e a partir de múltiplos olhares que estabelecem variadas prioridades. Mas, cabe salientar que analistas do referido plano conseguem perceber e deter-se sobre a complexidade desafiante da Educação de Jovens e Adultos (EJA) (CARA, 20I4), pois os alunos da EJA almejam ao conhecimento que foi interrompido ou ainda, que não foi alcançado. Assim, estes alunos voltam aos estudos com dificuldades tanto materiais como de aprendizagem (MEDEIROS, BASÉGIO, 2008), estabelecendo-se então a especificidade desta modalidade de ensino na medida em que também este retorno aos estudos pode ser considerado como um resgate, resgate de um saber, resgate social e de si mesmo, diante da invisibilidade que possuem as pessoas com pouquíssimo estudo neste país. São lapidares as palavras de Cara (20I4, p. I), quando afirma que:

Após ser um tema central entre as décadas de 1950 e 1980, a EJA tornou-se uma questão invisível no Brasil. Hoje ela reflete, como nenhuma outra, a incapacidade do país em consagrar o direito à educação. $\mathrm{E}$ pior: desnuda o descomedimento do Estado Brasileiro e de setores da sociedade com a questão social. De modo direto, três metas do PNE tratam da EJA. São as metas 8 (equalização dos anos de estudo da população entre 15 e 29 anos), 9 (universalização da alfabetização e redução do analfabetismo funcional) e 10 (articulação da EJA com a educação profissional).

A clareza do argumento de Cara (20/4), nos leva a profundas reflexões acerca da modalidade de ensino, objeto do presente artigo, pois na medida em que no campo educacional não são contemplados os determinantes do Plano Nacional de Educação (PNE), com relação à EJA, abre-se caminho para impasses e contradições presentes na forma de seus fazeres pedagógicos, fato propício para evasões e dificuldades no processo de ensino-aprendizagem, o qual exige mediações didáticas diferenciadas.

A Educação de Jovens e Adultos (EJA) tem suas particularidades a partir de seu nascimento, pois surge como uma forma de atender a um contingente populacional específico que necessitou abandonar os estudos em função de garantir sua sobrevivência. Nesta característica de fundação e função, temos outra que podemos e devemos considerar, pois exige um processo de mediação pedagógica que se diferencia do ensino regular, porque este prepara a criança e o jovem sequencialmente para o desenvolvimento de suas capacidades de abstração. Já o aluno da EJA, porque tem sua trajetória escolar interrompida, quando retorna aos estudos deve ser preparada para a referida capacidade, pois sua lógica e cognição encontram-se vinculadas às ações de cunho empírico. Então o aluno da EJA, necessita ser trabalhado a partir de sua realidade prática, pois ainda não dispõe de uma capacidade de abstração formada, sendo este, um elemento característico típico do aluno da EJA. Diz-nos, Balsanelli, (20I I, p.9) o seguinte: 
Não há idade para aprender. No entanto, um fator deve ser levado em conta: as pessoas que estão, há muito tempo sem contato com os conteúdos do currículo escolar (tanto de ensino fundamental, quando de ensino médio), ou que não possuem a cultura de lerem materiais diversificados sobre diferentes assuntos (ou não leem nada), estão propícios a terem um raciocínio e aprendizado mais lento.

O que significaria segundo o referido autor raciocínio mais lento? Mais lento com relação a que? Mais lento com relação à capacidade de abstração, pois se trata de sujeitos e subjetividades constituídas no mundo da vida e o mundo da vida é pleno de ações práticas que se realizam no cotidiano das casas, das ruas, do trabalho. Buscar-se a que estes indivíduos estejam incluídos na escola com a prática do ensino regular, envolve destiná-los a nova forma de invisibilidade a partir de seu capital cultural, o qual se configura enquanto raso e novamente destiná-los à invisibilidade social. Afirma Cara (2014, p.2), o seguinte:

O tema da EJA é espinhoso. Os governantes e a opinião pública preferem não abordá-lo, evitando tornar público o desrespeito ao direito à educação de dezenas de milhões de brasileiros. Assim, ao invés de pautar e enfrentar o problema, muitos governos e grande parte da sociedade brasileira limitam-se, a dizer que é "difícil e oneroso" empreender esforços para matricular jovens e adultos. Mais complexo ainda é mantê-los na escola ou em ações de educação popular. Mais grave é o fato de que, em muitos círculos do debate público e educacional, a EJA é tratada como um problema menor, a ser resolvido naturalmente pelo envelhecimento da população.

A aguda afirmação de Cara (20l4), nos permite perceber que é necessária e urgente maior discussões acerca dos impasses e contradições presentes no ensino da EJA em nossa realidade educacional, sob pena, de continuarmos a negar o enfrentamento do problema que se constitui o ensino da EJA e permanecermos a designar à invisibilidade social potencial contingente populacional. $O$ presente artigo em suas reflexões e discussões busca lançar questões e elementos para ser repensada a EJA no contexto educacional brasileiro, pois, na medida em que a recusa da abordagem dos extremos problemas desta modalidade de ensino incrementa a exclusão social via educação e não a inclusão necessária no âmbito da sociedade brasileira. Os autores citados neste artigo, são os autores que destinaram um olhar mais arguto sobre a EJA, buscando apontar os impasses e contradições existentes, fonte geradora do fracasso escolar presentes nesta modalidade de ensino. Metodologicamente, nos pautamos pelo estudo de caso como busca de respostas às nossas questões investigativas.

No primeiro momento o enfoque se dará por um breve resgate histórico da Educação de Jovens e Adultos (EJA) no Brasil. Num segundo momento, nos pautaremos pela análise e reflexões das aulas de matemática e história da referida turma T9 de ensino médio, enquanto resultados do trabalho de campo.

Cabe salientar que a Educação de Jovens e Adultos (EJA), no contexto da realidade educacional e social brasileira, envolve ser uma dívida social e, portanto, necessita ser refletida, questionada, para que o resgate desta dívida social seja presente na realidade dos alunos que a EJA buscam, por esta razão, carece cada vez mais fazer parte das discussões presentes no campo educacional brasileiro.

\section{Breve resgate histórico da Educação de Jovens e Adultos - (EJA) no Brasil}

Historicamente podemos verificar que um dos movimentos fortes no campo da alfabetização de adultos foi em nossa realidade educacional, o lançamento do Mobral, como campanha de alfabetização de massa em 1970 (PAIVA, 2003). Encontrava-se o Mobral, em estreita relação com a mobilização política do movimento estudantil de 1968 e em relação direta com a promulgação do Al-5, no governo do General Costa e Silva, fundando tal movimento, juntamente com a expansão do ensino superior um dos pilares da política educacional do governo militar de então (PAIVA, 2003). O Mobral instituiu-se como um dos pilares da estratégia de regulamentação do governo militar, de fortalecimento do regime, buscando ampliar suas bases políticas e sociais de legalidade junto aos segmentos populares. O Mobral foi ferramenta institucional junto aos segmentos subalternos da população, gerando regulamentação e empoderamento do novo governo (PAIVA, 2003). Então, neste sentido, o Mobral, constituiu-se como uma tática de manutenção e legitimação do poder militar. São significativas as palavras de Paiva (2003, p. 337) quando aponta que:

Nery et al. | Rev. Elet. Cient. da UERGS (2020) v. 6, n. 0I, p. 29-4 | 
[...] através do Mobral, o regime definiu também de maneira clara a sua linha de ação nacional em relação à educação popular. Por outro lado, ele dedicou vultuosos recursos à alfabetização da população adulta e se decidiu por uma ação centralizada e nacional em matéria de educação de adultos, ao mesmo tempo que descurou e descentralizou sempre mais o ensino fundamental. Por isso mesmo o Mobral pode ser apontado como o sucessor dos programas pós-64 em matéria de educação de adultos, ou seja, sucessor simultaneamente da Cruzada $\mathrm{ABC}$, como programa alfabetizador e do Projeto Rondon como programa de ação comunitária, mantendo ao longo da sua existência uma orientação análoga àquela que predominou nesses programas nos anos 60 e que foram - desde o início - intensamente criticados pelos profissionais da educação.

O que Paiva (2003), sinaliza, envolve a cooptação da Educação Popular por parte do governo militar para atender aos seus propósitos, por outro lado envolve ser o Mobral uma estratégia para dizimar e combater o autêntico movimento de alfabetização via educação popular que até a década de 70 estava de alguma forma presente na realidade educacional brasileira, sendo alguns fundamentos do método Paulo Freire de alfabetização empregado para jovens e adultos no que tange aos pressupostos políticos de consciência da realidade para a busca da transformação e transcendência da condição de oprimido.

O inegável sucesso da educação popular à época deveria para o regime militar ser de alguma forma "silenciada". De outra parte, cabe salientar que o Mobral foi uma campanha de alfabetização dotada de fartos recursos, ainda mais que seus recursos advinham de doação voluntária do imposto de renda das empresas e $24 \%$ do lucro líquido da Loteria Esportiva. Embora toda esta dotação orçamentária o Mobral não obtém o sucesso esperado pela manipulação dos resultados em relação à alfabetização e pelas intensas críticas dos profissionais da educação, com relação aos objetivos.

É importante esta primeira abordagem com enfoque no Mobral, porque foi através dele que o Regime Militar pôde cooptar em parte a Educação Popular. O Mobral foi estratégico para o governo vigente à época e cumpriu seu ofício, ou seja, não foi um sucesso em termos da alfabetização de adultos, mas em termos políticos e de manutenção e legitimação do poder, via educação cumpriu seu ofício.

Avançando no tempo histórico em nosso breve resgate, considerando a Lei de Diretrizes e Bases da Educação, Lei número 5.692/I97I, nela aparece um capitulo específico sobre a educação de jovens e adultos, o capítulo IV, que trata do ensino supletivo, tendo-se anteriormente os cursos noturnos e por fim a Educação de Jovens e Adultos (EJA). Mas deve-se ter em conta que a questão do ensino que possui como foco, jovens e adultos não é um problema novo na vida social brasileira. $O$ debate é intenso sobre aqueles que tiveram que abandonar seus estudos por falta de oportunidade, ou condições de possibilidade de segui-lo, acabando por ser excluídos da escola e, além disso, desprovidos do conhecimento e da formação que a escola oportuniza (MEDEIROS, BASÉGIO, 2008).

Constata-se na realidade educacional brasileira, que o retorno aos estudos, por parte de jovens e adultos, de significativo contingente populacional, envolve as escolas públicas, que oferecem a EJA geralmente à noite, pois, estes alunos possuem carências diversas e condições materiais de existência precárias, que buscam remediar suas privações sociais, econômicas, culturais e educacionais (MEDEIROS, BASÉGIO, 2008). Que não se conclua que as escolas privadas não ofereçam esta modalidade de ensino, a oferecem, mas a especificidade do público da EJA abarca pessoas com dificuldades econômicas, trabalhadores que lidam com parcos salários e ainda tem que se manter e manter suas famílias. São significativas as palavras de Medeiros e Baségio (2008, p. 36), quando apontam que:

Na maioria dos casos, esses alunos que abandonaram os estudos durante o período regular e/ou nem chegaram a ingressar na escola. Tomaram essa atitude em consequência de sua condição socioeconômica. A necessidade, desde muito cedo, de ter que contribuir para o sustento da família é um grave problema que milhares de brasileiros enfrentam diariamente e é uma situação que o Brasil ainda não eliminou da sociedade. Essa é uma lamentável chaga social. Não há como negar sua presença na vida diuturna e, para se constatar esse fato, basta se percorrer as ruas das grandes cidades brasileiras. É evidente que não é apenas a questão financeira que afastava, e afasta os alunos da escola. Existe uma série de fatores que contribui para esse processo de exclusão escolar. Entre eles, os altos índices de reprovação no ensino regular também se somavam, e ainda se somam, 
aos muitos motivos que fazem com que os alunos abandonem a escola e os estudos. $\mathrm{O}$ fracasso escolar está intimamente ligado à desmotivação, por parte dos alunos, no que se refere à continuidade dos estudos. É claro que esse se soma a muitos outros problemas, como as dificuldades financeiras que geram a obrigatoriedade de contribuir com um salário em casa, para o custeio das despesas e a sobrevivência do grupo familiar.

Nas afirmações dos referidos autores, dentro da realidade dos alunos que num momento de suas vidas decidiram e decidem retornar aos estudos anteriormente abandonados, podemos verificar a presença de um elemento histórico - estrutural e estruturante da realidade brasileira em suas dimensões educacionais, políticas, econômicas e culturais - a desigualdade social. Esta atravessa e interpela o campo educacional e gera ausência de reconhecimento social e invisibilidade para aqueles que na pirâmide social habitam a sua base. Cara $(2014$, p. 3) afirma que: "No Brasil atual, parcela significativa da população inicia o ensino fundamental, mas cerca de metade dos que ingressam nele não concluem o ensino médio na idade esperada." Com relação a este aspecto apontado por Cara (20I4), pode-se inferir que esta modalidade de ensino no contexto da finalização da educação básica brasileira, necessita ser amplamente refletida e considerada dado o contingente populacional que abrange.

Certifica-se que a flexibilidade presente anteriormente no ensino supletivo, levou a que na EJA houvesse elevada evasão, na medida em que o processo educativo reduzia-se a uma aprendizagem baseada em módulos instrucionais, não abrangendo a construção de um espaço de socialização e de vivências educativas (CORSO, ALMEIDA, 20I5). E, historicamente o sistema educacional público brasileiro não garantiu de forma plena o acesso da população à educação. No período do desenvolvimento urbano-industrial brasileiro, nas décadas de 50/60, poderia se pensar que sim, mas ambicionava essencialmente com a criação dos cursos profissionalizantes, a sustentação do mercado e também à manutenção da plataforma industrial emergente, ou seja, buscava gerar força de trabalho para a indústria. (MEDEIROS, BASÉGIO, 2008).

O Plano Nacional de Educação (PNE), por muitos tem sido debatido pelos mais variados enfoques e priorização diferenciada. Mas percebe-se que as metas mais desafiadoras dizem respeito à questão complexa - A Educação de Jovens e Adultos (EJA), por vezes quase esquecida e carente de discussões e reflexões aprofundadas que permitam questionamentos, pesquisas e estudos os quais possam levar à efetiva produtividade e garantia eficaz do direito à educação de significativo contingente da população brasileira.

Neste nosso breve resgate histórico do advento da EJA, em nosso contexto educacional, podemos esquematicamente mencionar: Mobral - Supletivo - EJA - PNE, como a matriz de uma realidade posta que ainda necessita ser refletida com profundo comprometimento por parte de educadores, pois, sem os quais não se poderá atacar ao problema do transformar parte considerável da população apenas como matéria-prima, sendo concebida como mão de obra à mercê do mercado de trabalho, com custo demasiado baixo, desatendendo-se o humano direito à educação.

\section{Resultados da observação de campo - olhares sobre a educação de jovens e adultos (EJA): a aula de Matemática}

Primeiramente, deve-se compreender que uma observação de campo é sempre um trabalho investigativo de caráter etnográfico. A observação teve como objetivo específico investigar, interpretar e analisar, as contradições e os impasses presentes na Educação de Jovens e Adultos (EJA), através da didática utilizada no processo de ensino-aprendizagem. Buscou-se também inteirar-se do planejamento, da rotina na turma do Ensino Médio - T9, em escola Estadual da cidade de Cruz Alta/RS, onde pudemos vivenciar duas experiências de mediações didático-pedagógicas, sendo uma em aula de Matemática e outra em aula de História.

A escola observada não se situa no centro da cidade de Cruz Alta/RS, mas da mesma forma não pode ser considerada uma escola especificamente da periferia. Verifica-se que atende essencialmente ao segmento econômico caracterizado na atualidade como classe $C$ e D, ou seja, segmento social que se encontra na base da pirâmide socioeconômica. $\mathrm{Na}$ escola referida verificamos uma novidade. São as salas de aula que "traduzem" as matérias. A sala de aula $20 \mathrm{I}$ exemplificando é a sala destinada às aulas de Matemática, assim sendo para as demais matérias do currículo escolar. Portanto, são os alunos que trocam de sala de acordo com a disciplina presente suas agendas de horários, conforme suas matrículas. Da mesma forma o professor permanece na sala de aula e recebe os seus alunos

Nery et al. | Rev. Elet. Cient. da UERGS (2020) v. 6, n. 0I, p. 29-4 I 
A turma observada - T9 tem seus períodos de aula divididos em dois e as aulas se realizam no período noturno. É uma turma de faixa etária heterogênea e consequentemente de interesses heterogêneos, o que se constitui num traço característico típico das turmas da EJA. O primeiro período da noite da turma T9 foi com a aula de Matemática, contando com a presença de 17 alunos, dos 28 matriculados. Os conteúdos trabaIhados foram: Área, Figuras geométricas Planas, Triângulos, Fórmulas sobre Área e um exemplo de problema sobre figuras geométricas. Considerando estas temáticas da aula, um aluno realizou um questionamento. Verificamos que a professora buscou responder à inquirição como se estivesse numa turma de ensino regular, ou seja, numa turma na qual o raciocínio abstrato já estaria mais desenvolvido, sendo assim respondeu rapidamente, assinalando os elementos das formulas no quadro, sem uma relação dialógica.

No cenário da aula de Matemática, os alunos de faixa etária maior, em media 48 anos de idade, menor grupo de pessoas, sentam-se na frente e há um grande grupo de faixa etária jovem, em média com 20 anos de idade, sentados em grupos no fundo da sala. A sala da aula possui vários cartazes com fórmulas de Matemática, símbolos matemáticos e conceitos sobre: Hipotenusa, catetos: oposto e adjacente; além das fórmulas de área distribuídas pelo espaço. Outro fator que chamou a atenção foi à desorganização dos materiais na prateleira do fundo da sala, existem livros abertos, outros fechados e alguns jogos. Também havia papel crepom e outros materiais em desorganização, retirando uma aparência acolhedora da sala de aula. Há traços característico típico, que nos parece interessante por duas razões: I) as pessoas de faixa etária maior procuram estarem mais próximas da professora; e, os alunos de faixa etária menor procuram agrupar-se no final da sala de aula; 2) a presença maior de jovens na faixa de idade de 20 anos.

Com relação a primeira razão, verifica-se que as pessoas de maior idade estão mais interessadas em aprender, em entender, por isso sentam-se mais próximas ao quadro e mais próximas da professora, para ouvi-la de melhor forma e copiar ao conteúdo. Este fato parece ocorrer porque são pessoas que já possuem uma trajetória de vida significativa, trazem consigo saberes e valores que prezam e voltam a estudar para atender a um objetivo para si, e, portanto, o retorno à escola tem um conteúdo de sentido mais elaborado, porquanto, pode significar um resgate social e cultural para consigo mesmo, possuindo então um aporte subjetivo significativo.

A segunda razão se apresenta enquanto dado de realidade grave da EJA, pois se identifica a contradição existente nesta modalidade de ensino, qual seja a perda de sua função social original. Neste enfoque a maior parte dos alunos é jovem e sendo assim deveriam estar no ensino regular. Mas não estão. O que ocorre? Que fatos novos estão a ocorrer? Bem, a EJA, não nasceu para atender a alunos em idade de cumprir o ensino regular, está a atender, porque estes alunos repetiram varias vezes disciplinas no ensino regular; porque muitos destes alunos abandonaram os estudos, não para trabalhar, mas por desencanto do mundo educacional, que depois por pressão dos pais, ou até mesmo das empresas em que possam trabalhar, voltam a estudar; ou, ainda, porque as escolas procuram colocar os alunos indisciplinados no ensino regular na EJA, no noturno. O que podemos dizer é que a EJA está sendo modificada em suas funções paulatinamente e deixando de cumprir sua real função social, destinando-se mais para jovens "rebeldes" no ensino regular, por exemplo. Salientamos que na permanência destas contradições, pode-se decretar o próprio fim da Educação de Jovens e Adultos, o que seria uma lástima para o ensino brasileiro.

Outro elemento significativo presente na segunda razão envolve o que está ocorrendo na contemporaneidade nas escolas sejam elas públicas ou privadas com relação ao jovem. Estes não vão para a escola estudar, mas vão para a escola encontrar-se com seus amigos, com seu grupo. Sendo assim a escola torna-se cada vez mais um espaço de encontro social para o jovem do que propriamente de aprendizado, porque é ali que podem todos estar juntos. Este é um traço cultural muito sério que está a acontecer no campo educacional que muito poucos educadores parecem estarem se dando conta, quando se trata de refletirmos sobre a significação da escola para o jovem hoje.

Sabemos que os conceitos matemáticos são inseridos desde nossa infância e que acompanham o crescimento particular de cada indivíduo estando presentes em várias situações do cotidiano, mesmo assim é possível detectar nos alunos um determinado anseio e medo relacionado a esta disciplina, a qual é considerada por inúmeros estudantes como uma das disciplinas mais complexas e difíceis do currículo. Tratando-se de uma aula da EJA, é preciso analisar as dificuldades de aprendizagem dos alunos, o ritmo de aprendizagem da turma e manter frequente relação dialógica, resignificando o cotidiano e fazendo com que o aluno seja agente da construção de seu conhecimento, evitando-se a exclusão. 
Constatamos a contradição seguinte: a professora estava a reproduzir a mesma metodologia empregada ao ensino regular e destinada aos alunos do diurno, pois houve a desconsideração do fato de que o aluno da EJA, já sofreu um processo de exclusão e quando voltam aos estudos são receptáculos de uma metodologia tradicional. O que este fato ocorrido ocasionará? Uma nova exclusão e sensação de fracasso individual. (MEDEIROS, BASÉGIO, 2008). Afirma Forell et al. (20I4, p. I5) que:

O professor, considerado como educador da EJA, parte do pressuposto de que se conheça a EJA como um todo: uma modalidade de ensino da educação Básica que difere das concepções e práticas mais gerais vigentes e presentes no Ensino Fundamental e Médio e que tem, a partir dos sujeitos que a constroem, algumas especificidades.

Então, parece claro que os professores da EJA, devem levar em conta seu público-alvo, a comunidade, as individualidades, as subjetividades, as características específicas e necessidades de sua turma, bem como seu ritmo, seu tempo de aprendizagem, para poder oportunizar aos seus alunos uma prática educativa, um fazer pedagógico mais voltado para a realidade cotidiana destes, o que significa inclusão no mundo escolar e no mundo social. Fazer o contrário, como dito anteriormente, é gerar uma nova exclusão. Ao verificarmos este fato, o impasse ficou demasiado claro, o ministrante não estava dotado do preparo para lidar com as especificidades dos alunos da EJA. Não podemos trabalhar com aquele que possui especificidades em seu existir, traços sociais e culturais característicos típicos como se fosse parte de procedimentos regulares. Atentemos para Scheibel e Lehenbaner (2006, p. 118), quando afirmam que:

Entendemos que os educadores de EJA devem ser profissionais com uma formação adequada para trabalhar o conhecimento matemático de forma a garantir a aprendizagem dos alunos. Para isso, pensamos ser de suma importância que os professores conheçam os processos cognitivos envolvidos na construção do conhecimento matemático pelo sujeito adulto.

Outro impasse que se pôde verificar é que esta inadequação metodológica, não atinge somente ao aluno, mas também ao professor, na medida em que, aluno desmotivado, também envolve ter-se professor desmotivado, assim "o professor faz que ensina e, o aluno faz que aprende", como é prática discursiva costumeira no meio educacional brasileiro.

A situação vivenciada por nós na aula de Matemática mostrou inclusive que a escola mesmo tendo a modalidade EJA, não disponibiliza os meios necessários para o resgate social e educacional destes jovens e adultos, os quais chegam sem esperanças, como resultado de um processo de exclusão social e com profundos déficits de aprendizagem, a começar pela preparação dos professores para ministrar esta modalidade de ensino, pois claro ficou que: os conhecimentos não sendo agregados à vida cotidiana dos alunos, não origina motivação para os estudos. Entendemos que aprimorar metodologicamente a Educação de Jovens e Adultos, seria significativo e urgente a capacitação necessária se buscarmos repensar e trabalhar com a Educação de Jovens e Adultos (EJA). São significativas as palavras de Medeiros e Baségio (2008, p.5I), quando apontam que:

[...] a EJA assume uma responsabilidade muito grande e muito importante dentro do contexto social brasileiro, pois sua missão é resgatar esses alunos que retornam receosos e amedrontados em consequência das experiências anteriores que os alijaram da escola. Os alunos da EJA, de um modo ou de outro, foram excluídos e, excluídos duplamente, primeiro pela sociedade e segundo pela escola que não soube fixá-los no contexto escolar. Esse fato, por si só, já é perverso e lamentável, uma vez que objetivo da escola é justamente o oposto: a integração e a inclusão. Essa situação, qualquer que seja, faz toda a diferença, uma vez que a escola tem que disponibilizar os meios necessários e apropriados para resgatar esses jovens e adultos que, na maioria das vezes, chegam desesperançados, com um grande déficit de aprendizagem e com muitas dificuldades para acompanharem e agregarem os conhecimentos que são ministrados nas escolas e que, em grande parte, não possuem nenhum significado para as vidas deles no cotidiano.

Nery et al. | Rev. Elet. Cient. da UERGS (2020) v. 6, n. 0I, p. 29-4 I 
Diante da realidade nacional na qual o determinante estrutural da desigualdade social atravessa o campo educacional uma modalidade de ensino como a EJA torna-se essencial para um processo de resgate social, educacional e cultural de indivíduos e grupos, mas parece que não há vontade política do Estado nacional de instrumentalizar adequadamente a EJA, partindo da preparação de professores, o que é grave e fonte geradora de nossos fracassos educacionais ainda mais no contexto de um mundo contemporâneo no qual o conhecimento é fonte de riqueza.

Assim, deixamos relegados à insignificância e invisibilidade social, jovens e adultos no contexto de nossa sociedade, não lhe oferecendo condições de possibilidade de resgatarem-se através do desenvolvimento de suas potencialidades e saberes. É uma dívida social imensa e um dano colateral profundo para um segmento significativo da população brasileira e, talvez como professores, poder, ser partícipes deste processo se não atentamos para as dimensões de nosso público-alvo.

Não devemos pensar a EJA, como uma modalidade de ensino homogeneizada, uniformizada em seu funcionamento e forma de organizar-se. É ponto salutar que Estado e municípios organizem a forma de funcionar de EJA. Esta tem particularidades e características típicas próprias, que obedece aos contextos regionais, municipais em suas especificidades e não poderia ser de outra forma dada a diversidade regional e cultural brasileira. Portanto, não se pode pensar uma organização curricular para EJA uniforme, padronizada, é uma contradição grave, que está presente no campo educacional brasileiro, pois, não se pode homogeneizar o diverso, buscar isto é um dano à educação, à sociedade brasileira como um todo. Medeiros e Baségio (2008, p. 52) afirmam o seguinte:

\begin{abstract}
A sociedade brasileira é muito rica e plural, cheia de contrastes e diversidades que se coadunam formando uma nação chamada Brasil. E é nesse contexto que se insere a EJA, em um universo repleto de matizes diferenciados, de região para região, com especificidades e necessidades diferenciadas. Por isso, não é possível estabelecer uma política de padronização do ensino de forma una para todo o país. Essa é uma visão excludente e ultrapassada que no passado era vista com bons olhos, principalmente durante a época em que prevaleceram os governos do Regime Militar.
\end{abstract}

A partir de 1985 entramos no período histórico da redemocratização do país. Poderia se dizer que o país é outro, principalmente no campo educacional, mas é? Não podemos negar que houve desenvolvimento no campo educacional de 1985 para cá, mas ainda falta muito e estruturalmente a educação não sofreu as devidas transformações necessárias, é preciso muito mais para além dos muros das escolas para melhorar a educação brasileira, é a questão da vontade política da diminuição da desigualdade social.

A escola é instituição social e sendo assim não está apartada das contradições e das relações de poder presentes no campo da sociedade envolvente. Assim a escola e o processo educativo precisam ser analisados em conformidade com as demais peças sociais, culturais, economia e política. Precisa ser analisadas, refletidas, questionadas dentro de todo um cenário político, econômico, social, cultural mais amplo. Caso contrário, seremos reprodutores da ignorância e da exclusão social como professores. São lapidares as palavras de Medeiros e Baségio (2008, p. 53), quando afirmam:

A educação é um componente da sociedade e não pode ser analisada separadamente dos demais componentes sociais. Da mesma forma que as disciplinas ministradas nas escolas não podem ser estudadas de forma isolada, estanque dos demais conteúdos, assim é a educação no contexto social: não há como obter progresso e melhoria sem que haja modificações nos demais segmentos que compõem a sociedade brasileira. E é justamente nesse cenário que a EJA se enquadra, em um mosaico de nuanças e conflitos de toda a ordem. Os alunos que procuram retomar os estudos almejam um lugar digno dentro dessa sociedade que há muito lhes tirou a única chance e/ou possibilidade de ascensão e de uma vida digna, conforme garante a Constituição brasileira.

É em trabalho investigativo que podemos ter a consciência dos impasses e contradições presentes na realidade do campo educacional e, a Educação de Jovens e Adultos, contem contradições e impasses em seu cenário e realidade que demandam ser questionadas se quisermos resgatar o ensino da EJA em sua real dimensão de recuperação social e cultural de indivíduos e grupos. 
A realidade objeto de nossa atividade investigativa na turma T9, na aula de Matemática, não se revelou transformadora, demonstrando-nos os problemas de repetência, aprovação sem assimilação de conhecimento e evasão escolar, podendo gerar inclusive fechamento de turmas. Um aluno com o qual conversamos nos disse que: "a professora explica muito rápido. Ela deveria dar a matéria de outro jeito para gente." Depois explicitou mais: "a professora explica muito rápido, a didática dela deveria ser diferenciada." Parece clara a realidade: encontra-se também na metodologia adotada pelos professores da EJA um dos elementos geradores da evasão, do desinteresse, da desmotivação.

E, pôde-se constatar que para um professor ministrar aulas na EJA ele deve ter uma preparação específica, diferenciada da preparação existente para o ensino regular, podendo assim, traçar estratégias metodológicas que gerem inclusão e envolvimento partindo da realidade cotidiana do aluno, de seus interesses, num processo constante de construção de uma identidade social positiva, fugindo da marginalização e da invisibilidade social.

\section{Resultados da observação de campo - olhares sobre a educação de jovens e adultos (EJA): a aula de História}

Para a aula de História a turma T9, dirigiu-se depois do intervalo para outra sala. Voltaram I 5 alunos, dos 17 que estavam presentes na aula de Matemática. O cenário da sala de aula de História era diferente, pois, não havia cartazes espalhados pelo ambiente, e os alunos seguiram distribuídos em fila ao modo tradicional; e não tínhamos jovens no fundo e alunos de mais idade na frente, ou seja, não tinha a junção de grupos nesta sala; todos chegavam e sentavam em suas classes enfileiradas; ao fundo da sala havia uma prateleira com os livros utilizados pela turma, ordenados de forma organizada e, os mesmos não continham os nomes dos alunos, na medida em que poderiam ser utilizados de forma aleatória, sempre que fosse necessário.

Esta aula nos surpreendeu diante do que havíamos constatado na aula de Matemática, muito mais pelo preparo do professor do que qualquer outra hipótese que se possa levantar. Ficou-nos claro o comprometimento do professor com seu saber e fazeres pedagógicos, sua proposta e sua prática, o que nos deixou a conceber, a possibilidade presente de modificar-se a educação e transformá-la em efetiva qualificação, na hipótese de que todas as instâncias envolvidas estejam fortemente comprometidas com esta tarefa a qual, no contexto sócio-histórico e cultural brasileiro é lapidarmos pedra bruta, a começar pelas relações de poder existentes, que determina a presença de uma educação para formar trabalhadores submissos e cumpridores de suas tarefas e uma educação para formar líderes qualificados para o mando. São significativas as palavras de Medeiros e Baségio (2008, p.72), quando apontam que:

Há a necessidade, por parte das elites, de desqualificar o saber popular, o saber cotidiano das camadas mais pobres da população. Em uma sociedade como a atual, na qual o saber é igual a ter, o poder está ligado a uma relação de posse de conhecimentos, isto é, aqueles que possuem o conhecimento se encontram em um nível superior da escala social. Ao resto da população cabe a obediência, uma vez que não possuem o conhecimento que Ihes possibilitaria galgar posições superiores na sociedade. As classes dominantes no Brasil sempre atuaram no sentido de impedir que as camadas populares promovessem uma leitura crítica da sociedade. Durante a segunda metade do século $X X$, a educação pública brasileira foi voltada apenas para a formação de mão - de - obra, logo, a reflexão sobre a sociedade e a atuação do povo na esfera política não era estimulada. Aos pobres bastava apenas aprender um ofício e deixar que o comando da nação ficasse a cargo das elites que eram preparadas para isso e que, de acordo com essa óptica, apresentavam as condições necessárias para fornecer os quadros governantes. Esse processo que levou a um ensino mecânico, descontextualizado e acrítico, é visível a partir da retirada de disciplinas, como o Latim e Filosofia, dos currículos escolares, pois elas podiam ser perigosas à ordem estabelecida, uma vez que estimulavam o aluno a pensar e a questionar a realidade.

A desqualificação dos saberes populares, da cultura e seus artefatos culturais é estratégia da elite dominante brasileira, que precisa manter uma massa da população desqualificada intelectualmente, quase aos pontos de miserabilidade para poder exercer seu poder e criar comportamentos de manada que lhe garantam falsa legitimidade. Talvez estejamos diante de uma das razões pelas quais a EJA está sendo cada vez mais deturpada, podendo chegar às vias de sua extinção. O que é extremamente preocupante. 
Os alunos se apresentaram bem participativos, pois, o professor dialoga o tempo todo com eles. A aula passou mais rápido, a didática foi diferenciada, partindo de questões problemas que tornaram a aula mais atrativa. O professor levou data show, e iniciou sua aula retomando os conteúdos que já havia trabalhado e perguntou se havia dúvidas, neste dia mostrava imagens da Segunda Guerra Mundial, ele também usou exemplos atuais e reais para somar as situações anteriores. Ele exemplificou os fatos históricos com exemplos atuais e reais. Ou seja, exemplos que inclusive os alunos encontram na mídia, principalmente na TV, no caso da condição social dos alunos, TV aberta, pois poucos podem possuir TV a cabo. Assim o professor trouxe para os alunos a história em termos empíricos, pois a poderiam comprovar em sua realidade cotidiana, por serem os fatos históricos exemplificados com elementos da realidade presente. Pensemos: este professor através do empírico não está a gerar a capacidade de abstração dos alunos? Não está ele permitindo a que os alunos desenvolvam esta dimensão humana que não puderam fazê-lo no tempo regular? Através da realidade concreta presente o professor retoma o passado estabelecendo a dimensão necessária ao humano de tempo-espaço.

Cabe destacar que há diferenças entre ciências humanas e ciências exatas em termos de abordagem metodológica, agora, no âmbito da EJA, é necessário que o professorado saiba que o conteúdo deve estar ao alcance da "vida vivida" do aluno, pois caso contrário, novamente, dizemos, seremos uma das matrizes causais da evasão escolar e do desencanto de jovens e adultos com o mundo educacional. Com relação à História e a necessidade desta ser ensinada e satisfatoriamente ensinada, é apontada por Aguiar e Mendes (2013, p. 9):

\begin{abstract}
Nada "é porque é". Tudo faz sentido sob a perspectiva da História. Dar significado ao passado é o que possibilita aos alunos a comunicação entre a história coletiva e a sua história individual, entre o que passou e o que está acontecendo; entre as diferentes experiências da humanidade e as possibilidades de escolha pessoal. Nesse sentido, os alunos também podem perceber-se como sujeitos da História, isto é, como construtores da sua biografia e como sujeitos atuantes no seu grupo social - família, escola, empresa e outras instituições das quais fazem parte.
\end{abstract}

Ao mesmo tempo em que as autoras mencionam a necessidade do estudo da História, demonstram uma metodologia para abordar determinado tema da matéria e trazermos os alunos para nossa aula.

Nesta aula o professor se utilizou do livro: "Viver e aprender Ciências Humanas, Ensino Médio - Tempo, espaço e cultura". Solicitou a que os alunos copiassem somente um trecho da página 327, e a aula ficou extremamente mais dialogada, inclusive os alunos de mais idade puderam dialogar também e se sentiram mais à vontade. Na media em que o professor solicita que os alunos copiem um determinado trecho, o objetivo é que procurem se apropriar da ideia principal do trecho e depois lançou para criar condições de possibilidade do diálogo uma "situação-problema". O professor, se não estava especializado, era muito interessado em dinâmicas de propostas educacionais que partem da "construção do aluno como agente de seu saber", assim - professor estimulava a participação e a relação dialógica, possibilitando que os alunos viessem refletir sobre o conteúdo ministrado. Inclusive a coleção que o professor adotou é exclusivamente destinada a alunos da EJA, o que demonstra que o professor sente-se mais à vontade nesta modalidade de ensino.

Após, foi abordado o conteúdo sobre Estado totalitário. Houve um questionamento de uma aluna e, a partir do mesmo, originou-se um debate sobre prefeito e presidente. Neste momento o professor trabalhou com a temática de interesse dos alunos, o que gerou salutar participação de todos e, o professor podemos dizer transformava o abstrato no concreto e trazia para a discussão. Assim, "o distante fica perto e o perto pode ser tocado, observado, abraçado", cremos que podemos dizer isso da realidade. O professor ainda para em alguns momentos ilustrar sua argumentação no diálogo com a classe, trouxe slides bem dinâmicos e atrativos, que potencializava mais a discussão, na medida em que traziam outros pontos para reflexão.

Podemos, portanto, verificando as duas situações- aula de Matemática - aula de História, considerar os impasses e contradições presente no universo da Educação de Jovens e Adultos que estão atreladas a utilização de práticas educacionais pautadas pela metodologia do ensino tradicional, na qual, seguindo-se Paulo Freire, encontramos uma educação bancária, no sentido de que o aluno é um depósito de informações e nada mais do que isso, e isso, tem significado político importante na medida em que: Como indica Freire, a alienação é o resultado de uma ordem social injusta, que leva aos oprimidos a ideia de serem menos. (MEDEIROS, BASÉGIO, 2008, p. 7I). É preciso levar em conta o ato educativo como um ato político e neste sentido, não se está aqui, a rememorar Paulo Freire, mas a compreender principalmente na contemporanei- 
dade $\mathrm{o}$ ato de educar como exigindo-nos gerar em nossos alunos da EJA, o desejo pelo pensar, pelo refletir, sua realidade, seu mundo, sua vida, pois a aprendizagem é sempre uma análise com olhar crítico para a realidade vivida, pois somente assim se pode supera-la, pela libertação da alienação imposta inclusive no campo educativo, já que é necessário urgentemente sair da condição de miseráveis intelectualmente que o processo de desigualdade social lhes legou.

\section{Considerações Finais}

Certamente, diante da complexa realidade da Educação de Jovens e Adultos (EJA), vigente no campo educacional brasileiro, não poderíamos abarcar todas as contradições e os impasses que nosso trabalho de campo permitiu observar nos limites de um artigo. Mas consideramos que se aponta como crucial a reflexão sobre estes impasses e contradições aqui mencionados sob pena, de deixarmos finalizar uma alternativa de estudo e conhecimento para aqueles que tiveram o seu direito ao conhecimento negado, por serem trabaIhadores e por viverem em condições precárias de existência.

O que está sendo sinalizado na contemporaneidade é praticamente o encerramento das turmas de EJA em muitas escolas, o que nos parece absolutamente grave, pois a EJA permite ao trabalhador, ou a um contingente significativo subalterno da população nacional retornar aos estudos e buscar atender aos seus objetivos e sonhos já com uma vida profissional definida.

Somente se poderia deixar fechar as turmas da EJA se em nossa realidade, em nosso contexto social não tivéssemos os determinantes da desigualdade social que leva a que indivíduos e grupos tenham que fazer duras escolhas em nome de sua sobrevivência. Não seria necessária a EJA, mesmo enquanto determinante do Estado se nossa realidade social, política, econômica e cultural facultasse as mesmas condições de possibilidade para indivíduos e grupos, mas esta não é nossa realidade e, assim, a EJA, não pode ter decretado o seu fim paulatinamente.

Verificamos que a invasão de jovens de 15 anos em diante nos cursos de EJA, constitui-se como um ato que desvirtua os reais fundamentos da Educação de Jovens e Adultos (EJA). Colocar-se em turmas de EJA, alunos que não tenham sido disciplinados, ou os chamados alunos-problemas no ensino regular, está se constituindo numa forma de destinarmos ao fracasso a Educação de Jovens e Adultos e o pior que por ação das próprias escolas, sejam públicas sejam privadas, fomentando e fortalecendo ainda mais a marginalização a descriminação dos alunos da EJA. Consideramos que é preciso repensar a EJA dentro do que ela tem de eminentemente positivo para a sociedade e o próprio campo educacional e não a considerarmos dentro de preconceitos que inclusive interpelam o professorado desta modalidade de ensino.

Diante da desigualdade social presente na realidade brasileira, que acomete o campo educacional, este não pode desconsiderar uma massa de indivíduos que são trabalhadores, muitos analfabetos, em condição de subemprego, ou mesmo que se encontram desempregados, ou ainda aqueles que estão submetidos a horas de serviço alternativa em seus turnos de trabalho, que precisam ter a oportunidade de regressar aos estudos e resgatar sua autoestima socialmente.

Sendo assim, existindo este contingente populacional deve ser atendido em suas necessidades enquanto mesmo respeito aos Direitos Humanos de dignidade, de respeito e de oportunidade e a EJA, no resgate que pode fazer, deveria ser mais bem tratada pelo Estado em suas políticas públicas, possibilitando ocasiões favoráveis para a inclusão deste segmento, tendo inclusive a adoção de uma metodologia que focalize, realce e evidencie a realidade do trabalhador e de seus cansaços.

$\mathrm{Na}$ realidade vemos nas escolas que possuem a modalidade de Educação de Jovens e Adultos (EJA), muitos jovens pararem de estudar e retomarem os estudos por pressão dos pais, sendo este um contingente maior do que os adultos trabalhadores, fonte geradora de profunda evasão e desinteresse que preocupa aos professores vinculados a esta modalidade de ensino, embora tenhamos constatado em nossa observação falhas do professorado, falhas da instituição, falhas dos órgãos governamentais, vinculadas ao processo de ensino-aprendizagem o qual diante de todos os demais problemas aglutinados à EJA, em termos metodológicos contribuem para a evasão intensa.

Uma das essenciais características da Educação de Jovens e Adultos (EJA) é o fato de que o aluno já é portador de um saber, ele tem posse de vivências as quais lhe permitem empiricamente traduzir sua realidade de algum modo, porque elaboradas a partir das relações sociais e dos instrumentos de sobrevivência, e, 
deve ser compreendido que seu ambiente cultural, com os artefatos culturais dos quais dispõem, como força motriz para a construção de seus saber via escola, evitando-se desta forma a sensação de fracasso.

É um preceito para adequada educação de jovens e adultos, compreender que o faltante é justamente a capacidade de trabalhar abstrativamente e neste fato se constitui todo o trabalho de ensino-aprendizagem da EJA que necessita ser feito, porque este sujeito-aluno não tendo o ensino regular, ou o tendo interrompido, não pôde aprender a abstrair e a escola, deve capacitar este adulto para ter o instrumental que lhe permita pensar e traduzir a sua realidade, traduzir o seu mundo.

Consideramos que nas assertivas acima se encontram elementos que nos permitem compreender a EJA dentro dos seus limites e de suas riquezas e, compreender também, que esta modalidade de ensino no contexto do campo educacional brasileiro em vez de ser valorizada e mais bem desenvolvida, pelo contrário está sofrendo com ausências, desinteresses das escolas e das instâncias governamentais, ou seja, por ausência de metodologia adequada utilizada, de recursos, de consideração de suas especificidades, do reconhecimento de sua importância. Fato que pudemos observar em nosso trabalho de campo que originou o presente artigo, com aulas que sinalizam para práticas de infantilização, contributivas para o processo de evasão e propulsora de uma dura sensação de fracasso. Convém resgatar o que menciona o Parecer CNE/CEB II/2000, (BRASIL, 2000, p. 5):

\begin{abstract}
[...] A Educação de Jovens e Adultos (EJA) representa uma dívida social não reparada para com os que não tiveram acesso a e nem domínio da escrita e leitura como bens sociais, na escola ou fora dela, e tenham sido a força de trabalho empregada na constituição de riquezas e na elevação de obras públicas. Ser privado deste acesso é, de fato, a perda de um instrumento imprescindível para uma presença significativa na convivência social contemporânea.
\end{abstract}

E, no resgate deste parecer acima mencionado, podemos verificar um problema sério presente no campo educacional nacional em sua totalidade, ou seja, o fato de que o texto não reflete o contexto e isto torna cada vez mais a educação deste país uma educação que está fadada ao fracasso enquanto as políticas públicas não vierem acompanhadas da vontade política de sua efetiva realização, caso contrário, ficamos no campo do texto contraditório às condições de possibilidade dadas pelo contexto.

Certificamo-nos em nosso trabalho de campo, que a utilização da metodologia tradicional de ensino bancária, não pode ser utilizada para aulas na EJA (ou para aula alguma), porque esta tem suas especificidades e constitui-se numa outra realidade, e que, portanto, aula expositiva dialogada, no contexto de uma relação dialógica possui maior eficácia pois, professor e aluno são possuidores de saberes, saberes diferentes e é justamente por isso que a relação dialógica pode se realizar. Não há um espaço para o professor autoritário, que oprime a liberdade do educando, tornando mesquinho seu direito de ser curioso e inquieto (FREIRE, 1997), há o espaço para o professor que dialoga permite a troca de ideias, permite as manifestações de inquietações e angústias, transforma a sala de aula numa "ilha" de troca de saberes e de acolhimento.

O trabalho investigativo realizado foi significativo e nos possibilitou o aprofundamento de nossos olhares à Educação de Jovens e Adultos, compreendendo seus impasses e contradições, bem como sinalizou para novos caminhos investigativos no campo educacional. E, constatamos que há riquezas nas interações entre faixas etárias heterogêneas, classes sociais diferenciadas, pois o efetivo conhecimento se faz na diferença, porque nesta é que se podem encontrar as compreensões mais profundas, força geradora do conhecimento efetivo que permite $o$ advento do pensamento complexo.

\title{
Referências
}

AGUIAR, Carolina Amaral de; MENDES, Denise. Manual do educador: história. São Paulo: Global, 2013.

ALMEIDA, Adriana de; CORSO, Ângela Maria. Educação de Jovens e Adultos. Anais do V SEMINÁRIO INTERNACIONAL DE PROFISSIONALIZAÇÃO DOCENTE. PUCPR, Curitiba, 2015.

BRASIL. CONSELHO NACIONAL DE EDUCAÇÃO. Câmara de Educação Básica. Parecer CNE/CEB I I/2000. Diretrizes Curriculares Nacionais para a Educação de Jovens e Adultos. Disponível em: www.mec.gov.br. Disponível em e-book: www.sabotagem.revolt.org Acesso em 20 Ago. 2018. 
BALSANELLI, Álice de Paula. Aprendizagem de jovens e adultos: a aprendizagem a seu tempo. 20I I. Monografia (Especialização). Curso de Psicopedagogia. Centro Universitário UNIASSELVI, Porto Alegre, $201 \mathrm{l}$.

CARA, Daniel. A Educação de Jovens e Adultos (EJA) é tratada de maneira míope e desumana. Folha do Professor. Sinpro Distrito Federal. 26 Ago. 2014. Disponível em: http://educacao.uol.com.br/colunas/daniel-cara/. Acesso em: 28 maio 2018.

FORELL, Leandro et al. Olhares Múltiplos e Contemporâneos da Educação de Jovens e Adultos. Porto Alegre: UERGS, 2014.

FREIRE, Paulo. Pedagogia da Autonomia: saberes necessários á prática educativa. São Paulo: Editora Vozes. 1997.

MEDEIROS, Renato da Luz; BASÉGIO, Leandro. Educação de Jovens e Adultos. Canoas: Editora da Ulbra, 2008.

PAIVA, Vanilda. História da Educação Popular no Brasil. Petrópolis: Editora Vozes. 2003.

SCHEIBEL, Maria Fani; LEHENBAUER, Silvania (Org); Reflexões sobre educação de jovens e adultos - EJA. Porto Alegre: Editora Pallotti, 2006. 